\title{
Prevalence and risk factors of urinary incontinence among women delivering in a tertiary care center of Northern India
}

\begin{abstract}
Introduction: Urinary incontinence (UI) is a common problem in antenatal and postpartum period. This study investigated the prevalence and risk factors of urinary incontinence in post partum women.

Methods: 500 women admitted in postnatal ward were interviewed using questionnaire over a period of six weeks. Detailed information regarding risk factors of urinary incontinence were included in questionnaire based on previous validated studies. Data was analyzed using SPSS 20 using chi square test. P value $<0.05$ was taken as significant.

Results: Total 500 women were interviewed and based on questionnaire 202 reported incontinence, thus giving a prevalence of $40.4 \%$, out of that $192(45.5 \%)$ had stress urinary incontinence (SUI), 40(19.8\%) had urge urinary incontinence (UUI) and $70(34.6 \%)$ had mixed incontinence. The risk factors like constipation and chronic cough had significant association with urinary incontinence. The symptoms of incontinence during pregnancy increased with advancing gestation $(\mathrm{p}=0.000)$.

Conclusion: Urinary incontinence is a common and neglected problem with poor healthcare seeking behavior. SUI is more common in pregnant women than urge or mixed incontinence. Obstetricians need to ask leading questions in pregnant women to diagnose the problem with intention to treat.

Significance: Urinary incontinence (UI) is known to have detrimental effects on quality of life in approximately $54.3 \%$ of all pregnant women. However, the true prevalence of UI is still not known, especially in the South East Asia. The purpose of this article is to emphasize on prevalence of this problem, creating awareness among the clinicians to deal with it. The article also emphasizes upon the risk factors leading to incontinence in peripartum period.
\end{abstract}

Keywords: prevalence, risk factors, urinary incontinence, questionnaire, treatment seeking behavior
Volume 3 Issue 4 - 2015

\author{
Bhanu priya, Neerja Goel, Nilanchali Singh \\ Department of Obstetrics and Gynecology, University of Delhi, \\ India \\ Correspondence: Nilanchali Singh, Assistant Professor, \\ Department of Obstetrics and Gynecology, University College \\ of Medical Sciences \& Guru Teg Bahadur Hospital, University of \\ Delhi, New Delhi, India, Tel 91-981 I343।68 \\ Email nilanchalisingh@gmail.com
}

Received: October 30, 2015 | Published: December 15, 2015

\section{Introduction}

Urinary incontinence (UI) is a significant health concern and has been shown to impair women's activities and also affects the physical and mental health. ${ }^{1}$ Studies on UI have reported a prevalence of $32 \%-64 \%$ for all UI and $40-59 \%$ for stress urinary incontinence (SUI) including mixed incontinence. ${ }^{2}$ Affected women have poorer health seeking behavior for UI. Approximately $54.3 \%$ of all pregnant women have detrimental effects on quality of life. ${ }^{3}$ Although, pregnancy is an independent risk factor for UI, irrespective of labor and delivery practices, however, despite the multiple references in literature, the pathophysiological effects of pregnancy and mode of delivery on the pelvic floor and lower urinary tract symptoms remain uncertain. ${ }^{4}$

Prenatal physiological changes such as increasing pressure of the advancing gravid uterus and growing fetal weight on pelvic floor muscle (PFM) throughout the pregnancy, along with the pregnancyrelated changing levels of hormones such as progesterone, estrogen, and relaxin, may lead to reduced strength and supportive and sphincteric function of PFM. ${ }^{5-8}$ PFM weakness causes bladder-neck and urethral mobility, leading to urethral sphincter incompetence. Hence, when intra-abdominal pressure is increased with coughing, sneezing, laughing, or moving, the pressure inside the bladder becomes greater than the urethral closure pressure and the urethral sphincter is not strong enough to maintain urethral closure. Urinary leakage will be the result. In particular, SUI is common during pregnancy and puerperium. After delivery, SUI symptoms resolve in the vast majority of cases $^{9}$. The healing process may take some time after the delivery, but in a significant percentage of women, it can persist in subsequent stages of life ${ }^{10}$. In primipara women, SUI symptoms tend to resolve within 3 month after delivery ${ }^{11}$.

Multiple risk factors have been associated with UI. Significant risk factors for UI in pregnancy were maternal age $\geq 35$ years, body mass index and parity. ${ }^{12}$ Smoking, diabetes, chronic cough and high intake of caffeine are identifiable risk factors for UI. ${ }^{13-15}$

The information available on UI in postpartum women from India is sparse. Therefore, a study on UI is designed which would add information regarding prevalence of UI in this part of world as incidence and prevalence estimates of incontinence vary widely. Only a few population based studies have investigated prevalence of urinary incontinence during pregnancy by type and severity. ${ }^{16}$ Also, data on risk factors for incontinence in pregnancy are scarce.

\section{Material and methods}

This observational study was carried out over six weeks in the department of obstetrics and gynecology, at a tertiary care hospital in Northern India. All the healthy postpartum women admitted in the 
post natal ward, who had singleton pregnancy, were included in the study. Total 500 subjects were included in the study. Informed consent was obtained from the participants prior to conducting the study and the women were interviewed about the given questionnaire.

\section{Definitions}

Urinary incontinence was assessed using standardized questions based on questions validated in previous studies. ${ }^{17,18}$ The questionnaire covered the risk factors, symptoms and severity of the UI. Women who had leakage of urine at least once a month, regardless of amount were defined as UI. Women were defined as having stress urinary incontinence if leakage of urine was associated with coughing, laughing, sneezing or physical activity, urge incontinence, if leakage was preceded or accompanied by urgency, and mixed incontinence when symptoms of both stress (SUI) and urge (UUI).

Urinary incontinence was present. These definitions follow the standardized terminology for lower urinary tract symptoms endorsed by the International Continence Society. ${ }^{19}$ Severity of UI was assessed as slight, moderate or severe based on the frequency and amount of leakage using the incontinence severity index. ${ }^{17,18}$ The questionnaire was used to gather information about socio- demographic pattern, predisposing and risk factors, health seeking behavior including the prevalence of UI. Data analysis was done using SPSS version 20. Odd's ratio and chi- square test was used for univariate analysis.

\section{Observations and results}

During the study, 500 women were interviewed. The mean age of study population was 25.1 years with a range of $19-40$ years. The demographic characteristics like age, weight, height, BMI, parity and past delivery mode were not found to have a significant association with UI Table 1.

Out of 500 participants, 185 primipara participated in study and of those 185 participants, 81 subjects reported incontinence. The prevalence of incontinence was $43.7 \%$ in primipara. Similarly, 315 multipara took part in the study and 163 had incontinence which gives a prevalence of $53.4 \%$ in multipara women.

In the study population chronic cough $(\mathrm{p}=0.001)$ and bladder infections $(p=0.013)$ had significant association with UI. Table 2 shows $\mathrm{p}$ value and odds ratio for the risk factors. Out of 500 women 202 reported incontinence, thus giving a prevalence of $40.4 \%$, out of that $192(45.5 \%)$ had SUI, 40(19.8 \%) had UUI and $70(34.6 \%)$ had mixed incontinence. Among the incontinent women 31/202 (15.3\%) sought treatment. The treatment seeking behavior was not related to severity of UI (Table 3) (Figure 1).

Table I Study group characteristics

\begin{tabular}{|c|c|c|c|}
\hline Characteristics & Group I ( $n=202)$ (Incontinence present) & 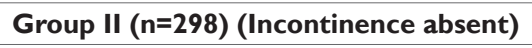 & $P$ value \\
\hline Age (years) & $25.1 \pm 3.2$ & $24.9 \pm 3.6$ & 0.703 \\
\hline Weight (kg) & $57.7 \pm 5.0$ & $57.6 \pm 5.1$ & 0.912 \\
\hline Height (cm) & $|5| .7 \pm 5.0$ & $151.9 \pm 5.2$ & 0.815 \\
\hline BMI $(\mathrm{kg} / \mathrm{m} 2)$ & $24.9 \pm 2.3$ & $25.0 \pm 2.1$ & 0.886 \\
\hline \multicolumn{4}{|l|}{ Parity } \\
\hline Primipara & 81 & 104 & 0.294 \\
\hline Multipara & 163 & 152 & \\
\hline \multicolumn{4}{|l|}{ Past delivery mode } \\
\hline No Past Delivery & 91 & 86 & 0.535 \\
\hline Previous Normal Delivery & 126 & 88 & \\
\hline Previous Cesarean Section & 76 & 33 & \\
\hline Bladder Habits Alteration & 371 & 129 & 0.187 \\
\hline Caffeine Intake & 203 & 297 & 1 \\
\hline Bladder Infection & 40 & 460 & 0.013 \\
\hline Pelvic Pain & 35 & 465 & 0.405 \\
\hline Chronic Cough & 48 & 452 & 0.001 \\
\hline Constipation & 11 & 489 & 0.15 \\
\hline
\end{tabular}

Table 2 Risk factors for urinary incontinence

\begin{tabular}{lll}
\hline Risk factors & Odd's ratio & $\mathbf{( 9 5 \% ~ C o n f i d e n c e ~ i n t e r v a l ) ~}$ \\
\hline Bladder Infection & 3.75 & $1.2-11.2$ \\
Pelvic Pain & 1.58 & $0.5-4.7$ \\
Chronic Cough & 4.99 & $1.7-14.5$ \\
Constipation & 3.23 & $0.7-13.3$ \\
\hline
\end{tabular}

Table 3 Frequency of urinary incontinence and treatment seeking behavior

\begin{tabular}{llll}
\hline Severity of UI & No. of subjects & Percentage & Treatment seeking subjects \\
\hline Slight & $42 / 202$ & $20.70 \%$ & $3(7.1 \%)$ \\
Moderate & $102 / 202$ & $50.40 \%$ & $15(14.7 \%)$ \\
Severe & $44 / 202$ & $21.70 \%$ & $8(18.1 \%)$ \\
Very Severe & $14 / 202$ & $6.90 \%$ & $5(35.4 \%)$ \\
\hline
\end{tabular}




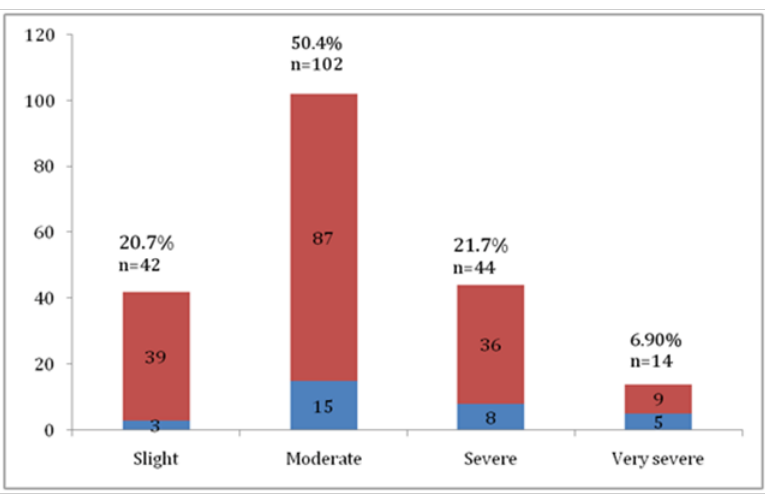

Figure I Bar diagram of frequency of urinary incontinence and treatment seeking behavior.

\section{Discussion}

Pregnancy is associated with lower urinary tract symptoms and UI is also very troublesome complaints. The most common type of UI is SUI. Subjects who had incontinence in our study was $40.4 \%$ which is in the range of the previous study in the literature.$^{20}$ In our study SUI was the most common form of incontinence (45.5\%) followed by mixed incontinence (34.6\%) and thereafter UUI (19.8\%). This was also in accordance to previous studies in the literature, which shows that SUI is the most common in pregnancy. ${ }^{21,22}$ The fact that SUI is the most common form of UI suggests that pelvic floor exercise can be used for effective prevention of SUI during pregnancy and postpartum period. ${ }^{23}$ It has been seen in the previous studies that six weeks pelvic floor muscle exercise programme was able to decrease the severity of symptoms of incontinence with SUI. Despite that nearly half of the pregnant women population was affected by UI, the treatment seeking behavior was only $15.3 \%$ of all incontinent women. It was also very interesting to note that only $6.9 \%$ of women with very severe UI did seek treatment.

The prevalence of incontinence in primipara was slightly higher than previously reported in literature. ${ }^{21}$ In our study $53.4 \%$ multipara had incontinence which shows that parity has association with incontinence. In this study sociodemographics pattern did not have any association with UI. Chronic cough and bladder infections had significant relation with UI. After univariate analysis the Odd's ratio for UI in subjects with chronic cough and bladder infections was 4-5 times more. Chronic cough itself has direct association with UI. ${ }^{24}$ Sudden increase in intra-abdominal pressure leads to exhaustion of pelvic floor muscles. Hence, UI was found to be more common with multiparity, chronic cough and bladder infections in our study.

\section{Limitations}

The study population was limited to our tertiary care center. Also, none of the subjects was examined gynaecologically for UI and UI was only inquired verbally which may reduce the accuracy of diagnosis.

\section{Conclusion}

A significant number of antenatal women are suffering from UI and it is substantially affecting the quality of life. The women in India are suffering from unawareness about the condition, hence making it difficult to diagnose for physician and further early treatment. Primary prevention of UI is needed by increasing public awareness about pelvic floor muscle exercise during and after pregnancy.

\section{Acknowledgments}

None.

\section{Conflicts of interest}

The authors declare there is no conflict of interests.

\section{Funding}

None.

\section{References}

1. Handa VL, Zyczynski HM, Burgio KL, et al. The impact of fecal and urinary incontinence on quality of life 6 months after childbirth. Am J Obstet Gynecol. 2007;197(6):636.e1-636.e6.

2. Milsom I, Altman D, Lapitan MC, et al. Epidemiology of urinary (UI) and faecal (FI) incontinence and pelvic organ prolapse (POP). In: Abrams $\mathrm{P}$ et al. (Eds.), Incontinence. 4th edn. Committee 1. Health Publication Ltd, Paris, France, 2009;37-111.

3. Dolan LM, Walsh D, Hamilton S, et al. A study of quality of life in primigravidae with urinary incontinence. Int Urogynecol J Pelvic Floor Dysfunct. 2004;15(3):160-164.

4. Koebl H, Nitti V, Baessler K, et al. Pathophysiology of urinary incontinence, fecal incontinence and pelvic organ prolapse. In: Abrams $\mathrm{P}$ et al, editors. Incontinence. 4th edn. Plymouth, UK: Health Publication Ltd; 2009:255-330.

5. Davis K, Kumar D. Pelvic floor dysfunction: a conceptual framework for collaborative patient-centred care. J Adv Nurs. 2003;43(6):555-568.

6. Morkved S, Bo K, Schei B, Salvesen KA Pelvic floor muscle training during pregnancy to prevent urinary incontinence: a single blind randomized controlled trial. Obstet Gynecol. 2003;101(2):313-319.

7. Hilton P, Dolan LM. Pathophysiology of urinary incontinence and pelvic organ prolapse. Br J Obstet Gynaecol. 2004;111(Sup.s1):5-9.

8. Kristiansson P, Samuelsson E, Schoultz B, et al. Reproductive hormones and stress urinary incontinence in pregnancy. Acta Obstet Gynecol Scand. 2001;80(12):1125-1130.

9. Viktrup L, Rortveit G, Lose G. Risk of stress urinary incontinence twelve years after the first pregnancy and delivery. Obstet Gynecol. 2006;108(2):248-254

10. Thom DH, Rortveit G. Prevalence of postpartum urinary incontinence: a systematic review. Acta Obstet Gynecol Scand. 2010;89(12):1511-1522.

11. Viktrup L, Lose G, Rolf M, et al. The frequency of urinary symptoms during pregnancy and puerperium in the primipara. Int Urogynecol $J$. 1993;4(1):27-30.

12. Cerruto MA, D'Elia C, Aloisi A, et al. Prevalence, incidence and obstetric factors' impact on female urinary incontinence in Europe: A systematic review. Urol Int. 2012;90(1):1-9.

13. Kirss F, Lang K, Toompere K, et al. Prevalence and risk factors of urinary incontinence among Estonian postmenopausal women. Springer Plus. 2013;2:524.

14. Swanson JG, Kaczorowski J, Skelly J, et al. Urinary incontinence: common problem among women over 45. Can Fam Physician. 2005;51(1):84-85.

15. Gleason JL, Richter HE, Redden DT, et al. Caffeine and urinary incontinence in US women. Int Urogynecol J. 2013;24(2):295-302.

16. Burgio KL, Locher JL, Zyczynski H, et al. Urinary incontinence during pregnancy in a racially mixed sample: characteristics and predisposing factors. Int Urogynecol J Pelvic Floor Dysfunct. 1996;7(2):69-73. 
17. Sandvik H, Hunskaar S, Seim A, et al. Validation of a severity index in female urinary incontinence and its implementation in an epidemiological survey. J Epidemiol Community Health. 1993;47(6):497-499.

18. Sandvik H, Seim A, Vanvik A, et al. A severity index for epidemiological surveys of female urninary incontinence: Comparison with 48-hour Pad-Weighing Tests. Neurourol Urodyn. 2000;19(2):137-145.

19. Abrams P, Cardozo L, Fall M, et al. The standardisation of terminology in lower urinary tract function: report from the standardisation sub-committee of the International Continence Society. Urology. 2003;61(1):37-49.

20. Bø K, PauckØglund G, Sletner L, et al. The prevalence of urinary incontinence in pregnancy among a multi-ethnic population resident in Norway. BJOG. 2012;119(11):1354-1360
21. Zhu L, Li L, Lang JH, et al. Prevalence and risk factors for peri and postpartum urinary incontinence in primiparous women in China: a prospective longitudinal study. Int Urogynecol J. 2012;23(5):563-572.

22. Hem L, Qamar-ur-Nisa, Jabeen A, et al. The Pattern of Urinary Tract Symptoms During Pregnancy. PakJ Med Sci. 2011;27(4):827-831.

23. Sangsawang B, Serisathien Y. Effect of pelvic floor muscle exercise programme on stress urinary incontinence among pregnant women. Gynecol Obstet Invest. 2012;68(9):1997-2007.

24. Perera J, Kirthinanda DS, Wijeratne S, et al. Descriptive cross sectional study on prevalence, perceptions, predisposing factors and health seeking behaviour of women with stress urinary incontinence. $B M C$ Women's Health. 2014;14:78. 